\title{
The Formal and Substantive Functions of the Principle of Proportionality
}

\author{
By ZoLTÁn PozSÁR-SZENTMIKLÓSY*
}

\begin{abstract}
This paper focuses on the principle of proportionality as a unique technique used in arguing judicial decisions dealing with fundamental rights disputes. I will contest that the principle of proportionality offers fixed steps of examination and makes the thought process of the court transparent. With this approach, conflicts of fundamental rights cannot be handled as zero-sum games, but as disputes in which it is possible to find a fair balance. Furthermore, the principle of proportionality offers a plausible method of controlling the quality of judicial decisions. The function of the principle of proportionality can be identified from different perspectives. Its formal function is to promote a valid and proper judgment. However, after closer examination one can argue that the formal function of the method is to support (a) the justifiability of the decision, (b) the correctness of the legal interpretation, and (c) the transparency of the arguments used. Besides, there are convincing arguments that the principle of proportionality has also an important substantive function in (a) offering more effective protection for human rights, (b) deepening the values of the rule of law, and (c) strengthening the democratic character of the decision-making process by the verifiability of the judicial argumentation.
\end{abstract}

Keywords: limitation of fundamental rights, principle of proportionality, verifiability of argumentation, legitimacy of judicial decisions

\section{INTRODUCTION}

The quality of the reasoning of judicial decisions dealing with fundamental rights is often challenging to measure. In most of the cases, there are no single "right" answers in these legal disputes due to the fact that even the exact meaning of certain fundamental rights can be unclear. However, the principle of proportionality offers a plausible method for courts to examine the acceptability of the limitation of fundamental rights in these legal disputes. If the method itself and the related steps of examination are clear, the reasoning of the court within this framework could be also subject to measurement: one has to compare the general requirements related to the method with its use in the case in question.

The requirements related to the methodology of the principle of proportionality are precisely described in the jurisprudence. However, it is often unclear as to what the core values it promotes are. To understand the related steps of examination and the method itself better, it is worth focusing on the role it plays. In this paper I will offer an analysis of the function of the principle of proportionality both from the formal and substantive points of view. After a closer examination, strengthening the justifiability of judicial decisions, the quality of the legal interpretation behind them and the transparency of the arguments used by courts can be considered as elements related to the formal function of the method. As to its substantive function, one can argue that it could offer more effective protection of fundamental rights, deepen values related to the rule of law and strengthen the democratic character of judicial decision-making.

* Assistant professor, Department of Constitutional Law, Faculty of Law, Eötvös Loránd University. E-mail: pozsarz@ajk.elte.hu 
Understanding the basic functions of the method better enhances its appropriate use by courts. More interestingly, it offers the possibility for the interpreter to measure the quality of judicial reasoning in fundamental rights disputes in a plausible way.

\section{FORMAL FUNCTION OF THE PRINCIPLE OF PROPORTIONALITY: CLASSIC APPROACHES EXPLAINED}

\subsection{Justifiability}

Every final decision on the constitutionality of a sub-constitutional law limiting a fundamental right is bound by circumstances which are typical of the judiciary: the case must be decided even if it is a hard one ${ }^{1}$ or there is neither political nor public consensus on the issue. Within these circumstances, it is of key importance that the decision be justifiable. Justifiability also has different layers: justifiability of the constitutionality (legality) of the decision, justifiability of the well-founded nature of the decision, and justifiability of the rational arguments leading to the final decision (instead of subjective intentions).

The judiciary has the right to some discretion when deciding legal disputes, but its sphere of action is not limitless. The final decision must be in accordance with the provisions of the constitution (or any other legal document protecting fundamental rights). The fundamental rights provisions of constitutions are often formulated in a very abstract way. However, they also refer (explicitly or implicitly) to the possibility of limitation. ${ }^{2}$ The decision of the court is in accordance with the constitution if it respects the rule of limitation, an aim which is achieved by using the steps of examination set by the principle of proportionality, ${ }^{3}$ designed specifically for this purpose. It is important to note that as a result of the abstract language of the provisions of the constitution, there is no other option for verifying the constitutionality of the decision.

Every judicial decision has to be supported by sufficient reasoning. In some respects, legal disputes concerning conflicts of fundamental rights are much more complex than other judicial cases, as the norms requiring interpretation are formulated in a very abstract language, and in most cases, the conflicting constitutional values are of equal importance. ${ }^{4}$

1 According to Davor Šušnjar, hard cases can occur under the following circumstances: (a) there is no statute or precedent applicable in the case, (b) legal language is vague, (c) norms are in conflict and it must be decided which one is applicable in a case, (d) it is possible to decide against the explicit wording of a provision, (e) the validity of legal rules may be questioned. See Šušnjar (2010) 11-12.

2 The possibility of limitation is also specified by the limitation clauses. A typical explicit "limitation of limitations" is the protection of the essential content of the fundamental rights. See Article 19. (2) of the Basic Law of the Federal Republic of Germany: "In no case may a basic right be infringed upon in its essential content.” The appropriate use of the principle of proportionality can have the same (implicit) limiting effect over the limitations of fundamental rights.

3 These are the examination of (a) the legitimate aim, (b) the rational connection between the means and the end (suitability), (c) the necessity of the means chosen by the legislator, and (d) the proportionality in the narrow sense, i.e. proportionality between the importance of the aim pursued and the harm caused by the limitation of the fundamental right. See Barak (2012) 3.

4 Although there are different approaches, for the purpose of this paper it seems appropriate to count on the Principle Theory of Robert Alexy. In his view, fundamental rights, as principles, are optimization requirements with equal value which gain for the highest possible realization. See Alexy (2010) 47-48. 
Within these circumstances, the appropriate use of the principle of proportionality can justify the well-founded nature of the decision, as the reasoning is structured and the fixed order of the steps of examination must be respected. It is also important that the relevant manner of the arguments used and the coherence and consistency of the argumentation ${ }^{5}$ is verifiable at every single step. The dissenting and the concurring opinions can be evaluated in the same way.

The sphere of discretion of the courts does not mean that decisions can be made arbitrarily. On the other hand, it is obvious that a judicial decision is not objective. ${ }^{6}$ This is even more visible in legal disputes regarding the limitation of fundamental rights. In these disputes, courts often have to rely on abstract and moral values in the argumentation, whereas the meaning of these values is defined by the courts themselves. The logical structure of the principle of proportionality requires coherent use of rational arguments. If moral values must be used in the argumentation, they can be introduced in the final stage of the examination (proportionality in the narrow sense), evading the risk that the decision is grounded on a false premise.

\subsection{Legal interpretation}

Every judicial decision is based on legal interpretation, however, this aspect becomes more emphasized in legal disputes regarding the limitation of fundamental rights. In these cases, the abstract language of constitutions needs to be clarified by the interpretation of superior courts, the use of the argumentation based on the principle of proportionality calls for an overall and careful interpretation of the provisions of the examined legal acts, and the methodology of the examination of sub-constitutional laws (i.e. the more precise formulation of the principle of proportionality within the given legal system) is the result of the interpretation of previous judgments.

Every legal dispute in this field starts with the interpretation of the provisions of the constitution related to the affected fundamental right. ${ }^{7}$ Relevant provisions of the constitution need clarification and the scope of the fundamental rights in question must be defined. The examination based on the principle of proportionality is a framework for both aspects of interpretation.

The interpretation of the sub-constitutional law limiting a fundamental right takes place entirely within the framework of the principle of proportionality. Identifying the legitimate aim of the legal provisions in question is only possible by interpreting the entire legal act. Similarly, examining the rational connection (suitability) of the means employed and evaluating them at the step of necessity (whether they can be considered the least restrictive means) calls for the interpretation of the legal act in the context of the legal system as a whole. Evaluating the relationship between the importance of the aim and the

5 Davor Šušnjar identifies coherence, consistency, universalizability and defeasibility as main principles of legal reasoning. See Šušnjar (2010) 34-45.

6 Regarding the principle of proportionality, David Beatty argues that objectivity can be gained by turning matters of interpretation and matters of moral principle into matters of fact. See Beatty (2004) 170-171.

7 This aspect is more visible in the case of examination methods containing two main stages: "The focus during the first stage of the inquiry rests on the ascertainment whether the scope of a right was satisfied in order for its protection to be released." This ascertainment can be grounded on the interpretation of the relevant provisions of the constitution. Regarding the one- and two-stage examinations see Schyff (2005) 11-14. 
harm caused by the limitation of the fundamental right in question (proportionality in the narrow sense) establishes a link between the interpretation of the constitution and the interpretation of the examined legal act.

Constitutions and other legal documents containing provisions on the protection of fundamental rights only rarely clarify the methodology of the examination of laws which limit fundamental rights. ${ }^{8}$ The superior courts usually establish their methodology in landmark decisions ${ }^{9}$, which are points of reference in future cases. When there is a need for correction, clarification or improvement of the methodology in question, the methodology itself (i.e. the specific framework of examination of the given court) has to be interpreted. In this sense, the use of the principle of proportionality calls for self-correction time after time.

\subsection{Transparency}

In my view, the third formal function of the principle of proportionality is to enhance the transparency of the structure of reasoning, the decisive legal arguments and the arguments based on moral values. This impact of the principle of proportionality is far more significant than the formal requirement of reasoning and the publicity of judicial decisions. Arguments based on the principle of proportionality enhance the precise identification of the most controversial moral and political questions society has to face, and lead to possible constitutional solutions.

The framework of examining sub-constitutional laws limiting fundamental rights is fixed $^{10}$ in the practice of every superior court. The steps of examination are settled in specific logical order whereby every aspect of examination is based on the findings of the previous one. The transparency and the stability of this framework enhance the possibility of verifying the coherence and consistency of the reasoning. If any step in the examination is missing or contradicts the findings of the previous one, it would be easy to detect. A transparent and stable framework of examination also helps the different branches of government to "speak a common language" in disputes concerning fundamental rights. ${ }^{11}$

8 One example is the limitation clause of the Hungarian Fundamental Law (i.e. the Constitution), which entered into force in 2012. The clause, referring more or less to the principles settled by the Constitutional Court, contains requirements regarding the possible limitation of fundamental rights, which are also a point of reference for examining the constitutionality of limiting laws. See Article I. (3) of the Fundamental Law of Hungary: "A fundamental right may be restricted to allow the exercise of another fundamental right or to defend any constitutional value to the extent absolutely necessary, in proportion to the desired goal and in respect of the essential content of such fundamental right."

9 See the Wencker decision (BverfGE 19, 342) and the Lüth decision (BverfGE 7, 198) of the Constitutional Court of the Federal Republic of Germany; the Handyside case [Case of Handyside $v$ the United Kingdom, 5493/72, (1976)] and the Sunday Times case [Case of Sunday Times $v$ the United Kingdom, 6538/74, (1979)] in the jurisdiction of the European Court of Human Rights; the Oakes case [R. v Oakes (1986) 1 S.C.R. 103] decided by the Supreme Court of Canada; and (from a different perspective) footnote 4 of the Carolene Products decision of the Supreme Court of the United States [United States v Carolene Products Company, 304 U.S. 144 (1938)].

10 This does not mean that the framework could not be clarified or even changed. As shown above, this is possible through the interpretation of the methodology itself.

11 In the practice of the Canadian government the examination of laws is also known prior to their enactment, (based on the methodology of the Supreme Court) so as to avoid future rulings of incompatibility with the Charter of Fundamental Rights and Freedoms. See Hogg (2009) 724. 
Due to the fixed framework, every step of examination needs separate argumentation, and the arguments used should be located in the chain of arguments at their proper place. Accordingly, the argumentation is traceable within the steps of examination. One can also find which arguments and counterarguments were challenged, which of those were denied and which were considered decisive. The transparency of the argumentation pushes the court to handle complex and controversial issues with plain and clear arguments.

It can happen that there is no single right answer to the question raised. When the law to be interpreted has no clear meaning, or there is no binding legal rule regarding the question, it is possible for a court to choose between the possible meanings, or to base its decision on moral considerations. The framework based on the principle of proportionality always makes these decisions transparent, and leaves open the possibility of denying or substituting the arguments leading to these decisions by future rulings. In cases where there is no single constitutional solution, the principle of proportionality also allows the court to show deference to the legislature. The transparency of the court's argumentation is important in guiding the other branches of government, as it indicates precisely to the legislature the issue to be addressed and the constitutional safeguards which limit its sphere of action.

\section{SUBSTANTIVE FUNCTION OF THE PRINCIPLE OF PROPORTIONALITY - RENEWING THE FOCUS}

\subsection{Protection of human rights}

The principle of proportionality is more than a method. Decisions of superior courts in cases related to conflicts of fundamental rights have significant impact on the entire legal and political system. One such effect is strengthening the system of protection of fundamental rights. This impact can be assessed from different perspectives, including the prevention of possible infringements of fundamental rights, offering effective remedy in individual cases, and offering appropriate methodology for other fora dealing with fundamental rights.

Every legal system has various institutions and proceedings which together build a specific system of protection of fundamental rights. Within these systems, the role of superior courts and constitutional courts is always of key importance, as their decisions are points of reference for other fora. If a superior court performs its examination properly, its abstract findings relating to the scope, role and nature of certain fundamental rights can guide the legislators and other courts to act in a way which respects these particularities. The proper examination based on the principle of proportionality ensures the correctness of these findings.

Individual cases can also be examined based on the principle of proportionality. In these cases the last part of the examination (proportionality in the narrow sense) can be more concrete, as the harm caused by the limitation of the fundamental right in the individual case can be weighed more precisely against the importance of the aim of the legal act in question. From this point of view, the framework of examination based on the principle of proportionality improves the efficiency of the protection of fundamental rights in individual cases. ${ }^{12}$

12 There are also critical opinions of this aspect. Criticizing the balancing stage of the principle of proportionality, Stavros Taskyrakis argues “... if constitutional rights protect the same kind of interests as those of the government, and if the protection depends on considerations of some kind of 
Conflicts of fundamental rights can also occur in the practice of other fora. Executive and legislative branches of government have a practical reason for examining their own legal acts prior to enacting them, as acts which have already been scrutinized will have a better chance of standing up to examination by the superior courts. Practical reasons also explain why it is worth focusing on the principle of proportionality during the prior examination, as this method may lead to the same result as the one found later by the court. Even if this aspect seems theoretical, practical examples do exist. ${ }^{13}$ Avoiding the most obvious impermissible limitations of fundamental rights strengthens the stability of the system of fundamental rights.

\subsection{Deepening the values of the rule of law}

The notion of rule of law is inseparable from judicial review. More specifically, the Constitutional Court of the Federal Republic of Germany derived the principle of proportionality from the Rechtstaat principle. ${ }^{14}$ Using the method properly also has an impact on the rule of law, as conflict between legal norms can be resolved and the right to legal remedy can be more effective. Furthermore, while carrying out the examination based on the principle of proportionality, courts can also identify certain substantive values which are part of the notion of the rule of law.

A formal collision is caused when legal acts are in contradiction with the provisions of a constitution or any other legal document with a priority position. The explicit or implicit limitation clauses open the possibility of limiting fundamental rights, and at the same time set boundaries to these limitations. ${ }^{15}$ A content-based examination, which aims to control the constitutionality of the limitation, also leads to the solution of the formal norm collision. From this perspective, the principle of proportionality offers a plausible method of enforcing the primary status of the constitution in cases related to fundamental rights, and also improves the consistency of the legal system.

The right to legal remedy is closely connected with the principle of fair trial and the rule of law. Taking this into consideration, one can also note that argumentation based on the principle of proportionality enhances the effectiveness of the legal remedy. If the examination of the legal act in question is made properly, the individual will have the chance to seek fair remedy in his or her case.

When examining certain legal acts limiting fundamental rights, courts always interpret the context of the case, taking into consideration the special circumstances and the relevant constitutional principles. The interpretation of the constitutional principles often leads to the decisive arguments of the case. When using the argumentation based on the principle of proportionality, courts always have to clarify the meaning and content of the abstract

relative 'weight' given to the conflicting interests, it follows that the protection accorded by the Constitution can never be stable...". See Tsakyrakis (2009) 468, 470. However, Matthias Klatt and Moritz Meister argue that the priority position of fundamental rights over public interests and balancing can be combined: "The higher the abstract weight of a right, the more likely it will trump competing considerations.” See Klatt et al. (2012) 687, 690.

13 See above note 12 regarding the practice of the Government of Canada.

14 See Schlink (2012) 730.

15 See above note 3 concerning the limitation of limitations. 
principles in order to balance precisely between the conflicting interests. This clarification often leads to the expression of the substantive values which formulate the rule of law. ${ }^{16}$

\subsection{Strengthening democratic decision-making}

Democratic decision-making is a multi-layered constitutional requirement. From the formal point of view it requires democratic legitimacy (rooted in the notion of people's sovereignty), and also values related to the process of decision-making of public authorities: transparency, debating competing alternatives, and respect for the minority opinion. ${ }^{17}$ The practice of courts based on the principle of proportionality fosters democratic decision-making in three ways. Firstly, it strengthens the legitimacy of the judicial decisions on a substantive basis. Secondly, it gives a sufficient sphere of action for the elected authorities in formulating social relations. Finally, it strengthens the system of checks and balances based on the notion of separation of powers.

An endless debate exists regarding the authority of the courts to make final decisions on essential social relations and liberties of individuals (e.g. questions relating to the beginning and end of life, the right to self-defense, etc.). Critics argue that only elected legislative bodies should have the final word on these issues, because they bear political responsibility to the public. On the other hand, it can be emphasized that a better option is for individual state organs to make the decisions, because they consider the law and not political expectations. Reasoning based on the principle of proportionality can also contribute to a softening of the tensions between democracy and constitutionality. ${ }^{18}$ The structured and transparent framework of argumentation makes the arguments decisive and the conclusions verifiable and justifiable. If properly used, the method also pushes judges to base their decisions on rational arguments instead of subjective intentions. They also evaluate the context of the case, as well as the social and historical circumstances. All these factors foster the possibility that politicians and the public will more readily accept judicial decisions. One can conclude that the principle of proportionality strengthens the legitimacy of judicial decisions on a substantive basis.

In conflicts of fundamental rights, it is also possible that there is no single right (constitutional) solution or that the possible solution does not follow from the text of the constitution in a compelling manner. Argumentation based on the principle of proportionality also promotes the detection of similar situations and encourages the consideration of whether there is a need for social consensus on the particular question. In the latter case courts can show deference to the legislator, which gives a sufficient sphere of action for the elected authorities in formulating social relations. ${ }^{19}$ The argumentation of courts can also guide legislators to find the proper solutions in this respect.

16 The founding president of the Constitutional Court of Hungary, László Sólyom [referring to the Decision 11/1992. (III. 5.)] underlines that "(T)the Constitutional Court has defined the rule of law as an institution which means more than the mere harmonization of laws and state activities with the provisions of the Constitution. It also held that the values and concepts of the Constitution ought to penetrate the society itself.” See Sólyom (2000) 28.

17 The concept of procedural requirements relating to decision-making can also be described by the notion of deliberative democracy.

18 Evelyne Maes argues that in cases related to the limitation of fundamental rights courts have to do two sets of balancing, "[...] firstly, between democracy and constitutionalism, and secondly, between the two conflicting constitutional rights.” See Maes, E., (2008) 70.

19 The concept of the margin of appreciation known from the practice of the European Court of 
The mere possibility of judicial review in cases involving fundamental rights is an element in the system of checks and balances which improves the judiciary's ability to control the legislative and executive branches. However, a transparent framework of examining legal acts based on the principle of proportionality makes the superior courts verifiable and accountable as well. From a substantive point of view, this gives a degree of control over the judiciary. Besides, due to the fact that judges and politicians can speak a "common language" on issues involving fundamental rights, the argumentation based on the principle of proportionality can also improve the cooperation between the different branches of government. ${ }^{20}$ Based on these outcomes, the proper use of the principle of proportionality can strengthen the system of checks and balances.

The quality of the argumentation of judicial decisions is verifiable when it is based on the principle of proportionality. If the method is properly used, the different steps of examination form a fixed, logical order. Due to the structure of the reasoning, the chain of arguments is always traceable and value judgments made by courts are transparent. These results strengthen the democratic nature of the judicial decision-making process. This is a good reason why it is worth learning how to use the method in an appropriate way.

\section{LITERATURE}

Alexy, R., A Theory of Constitutional Rights (Julian Rivers tr, OUP 2010).

Barak, A., Proportionality. Constitutional Rights and Their Limitations (Doron Kalir tr, CUP 2012).

Beatty, D., The Ultimate Rule of Law (OUP 2004).

Hogg, P. W., Constitutional Law of Canada. 2009 Student Edition (Carswell 2009).

Klatt, M. and Meister, M., 'Proportionality - A Benefit to Human Rights? Remarks on the I.CON Controversy' (2012) 3 International Journal of Constitutional Law 687-708.

Letsas, G., A Theory of Interpretation of the European Convention on Human Rights (OUP 2007).

Maes, E., 'Constitutional Democracy, Constitutional Interpretation and Conflicting Rights' in E Brems (ed), Conflicts Between Fundamental Rights (Intersentia 2008) 69-100.

Robertson, D., The Judge as Political Theorist: Contemporary Constitutional Review (Princeton University Press 2010).

Schlink, B., 'Proportionality (1)' in M Rosenfeld and A Sajó (eds), The Oxford Handbook of Comparative Constitutional Law (OUP 2012).

Schyff, G. van der, Limitation of Rights. A Study of the European Convention and the South African Bill of Rights (Wolf Legal 2005).

Sólyom, L., 'To the Tenth Anniversary of Constitutional Review' in G Halmai (ed), The Constitution Found? The First Nine Years of Hungarian Constitutional Review on Fundamental Rights (INDOK 2000) 21-47.

Šušnjar, D., Proportionality, Fundamental Rights, and Balance of Powers (Martinus Nijhoff 2010).

Tsakyrakis, S., 'Proportionality: An Assault on Human Rights?' (2009) 7 International Journal of Constitutional Law 468-493.

Human Rights has the characteristics of deference as well. For the specification of the notion see Letsas (2007) 84.

20 David Robertson emphasizes that "[t]he language of the courts becomes the language of other state actors", which is important from the point of view that language also "shapes decisions and revisions”. See Robertson, (2010) 346. 